\title{
EL ESTATUTO DE CATALUÑA A TRAVÉS DE LOS VOTOS PARTICULARES A LA SENTENCIA DEL TRIBUNAL CONSTITUCIONAL 31/2010, DE 28 DE JUNIO
}

\author{
ENRIQUE ÁLVAREZ CONDE \\ Catedrático de Derecho Constitucional \\ Universidad Rey Juan Carlos \\ ROSARIO TUR AUSINA \\ Profesora Titular de Derecho Constitucional \\ Universidad Miguel Hernández de Elche
}

\author{
SUMARIO \\ I. A vueltas con el significado de los votos par- \\ ticulares: \\ II. El contenido de los votos particulares \\ III. Conclusiones
}

\section{A VUELTAS CON EL SIGNIFICADO DE LOS VOTOS PARTICULARES}

A) La técnica de los votos particulares en la jurisdicción constitucional española

El art. 164 CE constitucionaliza, siguiendo los modelos del Derecho anglosajón donde muestra históricamente una fuerte inercia, y contrariamente a nuestra tradición histórica, la publicación de los votos particulares, si los hubiere, junto con las sentencias ${ }^{1}$. Esta cuestión ha sido ampliamente debatida en la doctrina ${ }^{2}$ manteniéndose, sustancial-

1 Cfr. Mattei,U., Il modello di Common Law, Torino, 2004, págs. 138 ss.

2 Cfr., a este respecto, Cámara Villar, G., Votos particulares y derechos fundamentales en la práctica del Tribunal Constitucional (1981-1991), Madrid, 1993; CASCAJO J. L., «La figura del voto particular en la jurisdicción constitucional española», Revista Española de Derecho Constitucional, n 17; EzQUIAGA, F. J., «El voto particular», Madrid, 1990; Fernández Segado, F., «La recepción del sondervotum en Alemania», Revista de las Cortes Generales, $\mathrm{n}^{\circ}$ 77, 2009; RolLA, G., Indirizzo politico e Tribunale Costituzionale in Spagna, Nápoles, 1986; RIDAURA 
mente, dos posturas: una, que afirma la necesidad de publicar los votos particulares, pues de esta forma se conoce mejor y se perfecciona pro futuro la doctrina constitucional erigiéndose, asimismo, en requisito para la independencia de los miembros del Tribunal; y otra, que postula que su existencia puede contribuir a la politización del Tribunal, ya que condiciona las decisiones de sus magistrados, los cuales podrán actuar de conformidad a las exigencias de las fuerzas políticas que propiciaron su designación.

A nuestro juicio, no obstante, tiene mayor solidez argumentativa la primera de las posturas por diversas razones. En primer lugar, porque muestra a la sociedad en general, y a los operadores jurídicos en particular, el debate en torno a la búsqueda del consenso y uniformidad en la doctrina constitucional. En segundo lugar, en tanto evidencia la dinamicidad y apertura del derecho constitucional a nuevas interpretaciones de la Carta Magna que, sin contravenirla, trascienden en muchas ocasiones las fronteras estrictas de dicho texto. En tercer lugar, porque los votos pueden servir, en un momento determinado, para el desbloqueo de una infructuosa búsqueda de consenso planteada en una situación especialmente crítica o tensa. Y finalmente, por cuanto los votos pueden mostrar en ocasiones los posibles puntos débiles de la técnica argumentativa y el anuncio de un posible - y quizá inminente- viraje doctrinal ${ }^{3}$. Todo ello tomando además en consideración que la politización del Tribunal Constitucional es una cuestión que sólo accidentalmente se relaciona con la existencia de los votos particulares. Los votos serían, de hecho, sólo un ámbito más donde podría mostrarse la posible «contaminación» del Tribunal, siendo más relevantes otros factores que contribuyen a este complejo problema, por lo que la politización de esta institución no guardaría, en definitiva, una relación directamente proporcional con la posibilidad de opiniones discrepantes en su seno.

Por lo demás, cabe añadir un argumento, si cabe, que otorga un peso adicional a los votos particulares cuando nos referimos con carácter específico al Tribunal Constitucio$\mathrm{nal}^{4}$. En tanto se trata de un órgano jurisdiccional cuyas resoluciones ya no son revisables por otras instancias judiciales, resulta especialmente importante tanto la coherencia de su doctrina con la finalidad de dar uniformidad y certeza al ordenamiento constitucional, como el hecho de que la legitimidad de su actuación pase a depender por ello mismo de factores que ya serían ajenos al sistema judicial. Ambos elementos enfatizan el valor de los votos frente a la «opinión del Tribunal», en una suerte de «sano constructivismo» 5 .

Finalmente, hay incluso algún autor que enfatiza el valor de los votos particulares como elementos para una positiva contribución del Tribunal a la colaboración de poderes. Así, aquellos servirían al electorado para el mejor control de las mayorías-minorías parlamentarias, pues el debate de constitucionalidad y, en particular, las diversas argumentaciones expresadas a través del parecer del Tribunal y de los posibles votos, por no

MARTínez, M. J., «La regulación de los votos particulares en la Constitución Española de 1978», en ÁLvarez Conde, E., Díez años de régimen constitucional, Madrid, 1989.

3 De hecho, es factible que el contenido de determinados votos acabe integrándose en la opinión del Tribunal.

4 En tal sentido, siguiendo la dinámica del modelo common law y de la posición del Tribunal Supremo respecto a la autovinculación a los precedentes, lo que en definitiva supone el respeto al método jurídico más estricto. Vid. MAGALONI KeRPEL, A. L., El precedente constitucional en el sistema judicial norteamericano, Madrid, 2001, pág. 53, así como la bibliografía citada por esta autora.

5 Cfr. Cámara Villar, G., Votos particulares y derechos fundamentales..., cit., pág. 17. 
citar el papel de la prensa al respecto, aportan contenidos sustanciales que pueden servir para la exigencia de responsabilidad en las urnas ${ }^{6}$.

En cualquier caso, en el fondo del debate sobre los votos particulares está otro de mayor calado cual es el de la existencia de certeza jurídica absoluta o de infalibilidad judicial, pues de lo contrario - como se admite habitualmente en el derecho de corte anglosajón-, sólo cabe partir de la premisa de que el derecho no es sino una cuestión de principios constitucionales en contradicción que son auténtico diritto vivente, y que dan lugar a distintas soluciones que competirían entre sî́.

La regulación efectuada, en particular, por la LOTC en su art. 90.2 establece la posibilidad de que, a través de los votos particulares, los Magistrados reflejen las opiniones discrepantes defendidas en la deliberación, tanto por lo que se refiere a la decisión adoptada como por lo que a la propia fundamentación de la misma atañe. Pero, además, los votos particulares caben en todo tipo de decisiones del Tribunal, habiéndose hecho un uso importante de los mismos, más frecuente si cabe en las sentencias más significativas y que mayor repercusión pública han tenido, y que afecta a entre un $10 \%$ y un $15 \%$ de las sentencias, según sea el periodo de tiempo que tomemos como referencia. De un análisis genérico se desprende una inicial valoración: mientras unas veces se han limitado a cuestiones estrictamente jurídicas, en otras han representado importantes discrepancias políticas, arropadas, eso sí, con criterios jurídicos.

Dentro de los votos particulares se aprecia tradicionalmente la distinción entre votos discrepantes (dissenting opinions) y votos concurrentes (concurring opinions). Los primeros vendrían referidos al fallo, y los segundos a la fundamentación de aquel, compartiendo su contenido, pero discrepando en todo o en parte de su argumentación. Incluso se puede dar el caso hipotético de que una mayoría apoye el fallo pero no la fundamentación del mismo.

La doctrina minoritaria expresada a través de los votos particulares carece de los efectos propios de las sentencias, las cuales reflejan la posición mayoritaria. Sin embargo, como anunciábamos, su importancia no puede desconocerse como elemento de evolución de la propia jurisprudencia constitucional, además de la necesidad de valorarlos como condición adecuada para favorecer tanto la formación de la voluntad del órgano colegiado, como el necesario consenso en la adopción de decisiones. Consideraciones a las que se suma el hecho de que su anuncio o posibilidad de existencia debe tender a generar, lógicamente, una mayor argumentación y motivación de las sentencias, favoreciendo, de este modo, la propia formación de la opinión pública. Por ello, no es de extrañar que algunas posiciones minoritarias del Tribunal se hayan convertido, con el paso del tiempo, en posiciones mayoritarias.

La utilización de los votos particulares ${ }^{8}$ puede obedecer a diversas causas que, en ocasiones, incluso se dan de modo simultáneo:

1) Por discrepancias interpretativas.

6 Vid. Hernando Masdeu, J., «El Tribunal Constitucional y la Separación de Poderes. El voto particular», Anuario jurídico y económico escurialense, no 35, 2002, págs. 310-311.

7 Sobre esta dicotomía, Mortati, C., «Le opinión dissenzienti dei giudici costituzionali ed internazionali», Raccolta di Scritti, Vol. III, Milán, 1972, pág. 856.

8 Así lo entiende EzQuiaga F., «El voto particular», cit. 
2) Por la distinta forma de entender la función que debe desarrollar el Tribunal Constitucional en su sistema de relaciones con otros poderes del Estado.

3) Podría guardar relación con la propia doctrina del Tribunal, en el sentido de si la decisión en cuestión se aparta o no de ella, aspecto éste que debe ser afirmado de forma expresa a través de una decisión adoptada por el Pleno del Tribunal, de conformidad con lo previsto en el art. 13 LOTC (overruling) ${ }^{9}$.

4) Podría traer causa de una advertida incoherencia o ausencia de motivación en el iter lógico de la decisión.

5) O finalmente, podrían ser formulados en coherencia con otros votos particulares anteriores.

B) La técnica de los votos particulares en la Sentencia 31/2010 del Tribunal Constitucional sobre el Estatuto de Autonomía de Cataluña. El Tribunal cambia, paradójicamente, de estrategia en la Sentencia 137/2010

En relación con los votos particulares a la STC 31/2010, la misma presenta la existencia de cinco votos, cuatro de ellos que afectan a la practica totalidad de la misma y uno, el del Magistrado Eugeni Gay, referente a cuestiones puntuales, y que carece de una mayor relevancia jurídica ${ }^{10}$.

Se suele afirmar que todos, la mayoría y la minoría, comparten una misma tesis, aunque la expresan de forma diferente: para unos, la mayoría, en muchos preceptos estatutarios es posible una interpretación conforme; mientras para otros, la minoría — expresada a través de los votos-, solo la declaración de inconstitucionalidad constituye una respuesta adecuada a dichos enunciados estatutarios. Sin embargo, esto es sólo parcialmente cierto pues, además, los votos particulares no tienen un carácter uniforme, ya que cada uno de ellos, además de los aspectos generales, en los cuales sí que existe un mayor grado de coincidencia, se centran de forma distinta en cuestiones puntuales y concretas. Lo cierto, de cualquier modo, es que las argumentaciones de los votos particulares se detienen más en las cuestiones generales, con especial mención al significado de las sentencias interpretativas y a la propia posición del Tribunal Constitucional, que en los aspectos particulares del Estatuto. Además, no todos tienen la misma dimensión ni presentan los mismos perfiles generales. Así, el voto de Eugeni Gay es puntual y testimonial, centrado fundamentalmente en los aspectos identitarios ${ }^{11}$. El voto de Ramón

9 Al respecto, vid. FERnÁNDEZ SEGADO, F., «Los overruling de la jurisprudencia constitucional», Foro. Nueva Época, $\mathrm{n}^{\circ} 3,2006$, págs. 27 ss.

10 Sobre el significado de la STC 31/2010, cfr. Tur Ausina, R., Álvarez Conde, E., Las consecuencias jurídicas de la sentencia 31/2010, de 28 de junio del Tribunal Constitucional sobre el Estatuto de Cataluña. La sentencia de la perfecta libertad, Madrid, 2010. Las demás sentencias pronunciadas sobre el Estatuto de Cataluña (nos referimos a las que desestiman los recursos interpuestos por los Gobiernos de la Comunitat Valenciana, Aragón, Islas Baleares, y Murcia (SSTC 48/2010, de 9 de septiembre; 46/2010, de 8 de septiembre; 47/2010, de 8 de septiembre; y 49/2010, de 29 de septiembre), donde no hay novedades sustanciales, también contienen cuatro votos particulares, la inmensa mayoría de remisión a los emitidos en relación con la STC 31/2010. Se aparta de esta técnica, como comentaremos con posterioridad, la Sentencia 137/2010, de 16 de diciembre, que trae causa del recurso de inconstitucionalidad planteado por el Defensor del Pueblo contra el Estatuto de Autonomía de Cataluña. Y tampoco contiene votos particulares la Sentencia 138/2010, de 16 de diciembre emitida por el Tribunal Constitucional a raíz del recurso interpuesto por el Gobierno de La Rioja contra determinados preceptos - muchos menos de los impugnados por el Defensor del Pueblo— del Estatuto de Autonomía catalán.

11 El contenido del voto afecta a la naturaleza y contenido de los Estatutos, a la regulación efectuada por el Preámbulo y el Título Preliminar, entendiendo que el adjetivo nacional aplicado a Cataluña no ha de con- 
Rodríguez Arribas es más condescendiente con la posición mayoritaria del Tribunal, existiendo cuestiones vitales en las cuales no manifiesta discrepancia alguna. Por su parte, los votos de Javier Delgado y Vicente Conde, los más parecidos entre sí, presentan una discrepancia fundamental con la doctrina mayoritaria. Y finalmente, el voto de Jorge Rodríguez-Zapata es el más discrepante de todos ellos, al menos en cuanto a las cuestiones generales se refiere, pues entiende que todo el Estatuto esta sujeto a «un vicio colosal de incompetencia» y que la decisión adoptada por la mayoría viene a determinar la existencia de una «sentencia oculta» conformada por todas las interpretaciones conforme no llevadas al fallo.

Ante esta situación, la pregunta que podríamos formularnos se refiere a la existencia de cuatro votos particulares que presentan muchas semejanzas entre sí, no tanto por lo que a su fundamentación se refiere, aunque sí por lo que a sus conclusiones atañe: ¿por qué no hubo un solo voto particular firmado por los cuatro magistrados, cuando los cuatro votos existentes coinciden en no pocas cuestiones?; ¿quiere decirse con ello que la mayoría estaba más cohesionada que la minoría ${ }^{72}$. Posiblemente nunca obtengamos una respuesta a estas preguntas, lo que no impide constatar los hechos. En tal sentido, se trata de poner en evidencia que los votos particulares fueron redactados una vez realizadas las correspondientes deliberaciones en el Pleno del Tribunal que son, como es obvio, secretas, siendo lo importante, al respecto, señalar que a la hora de su redacción, todos, incluida la mayoría, conocían las argumentaciones defendidas por los distintos Magistrados, lo cual pudo influir a la hora de redactar el contenido del voto particular en cuestión, así como la propia sentencia mayoritaria.

Por otro lado, hay que afirmar que la sentencia, ante la envergadura del tema sometido a su jurisdicción, y también ante las alegaciones efectuadas por los recurrentes y por las partes, podría haber realizado toda una construcción dogmática a tal efecto. Sin embargo, lo cierto es que ésta no existe en líneas generales. La opción mayoritaria se limita a defender sus argumentaciones, cuando lo hace que no siempre, acudiendo a un mismo planteamiento teórico: lo que hemos venido a llamar la sentencia de la «perfecta libertad». Es decir, poniendo de relieve la plena libertad de que dispone el legislador estatal y, en su caso, el propio Tribunal Constitucional en el ejercicio de sus competencias ${ }^{13}$. De este modo, ni responde a todas las argumentaciones de los recurrentes y de las partes, ni es congruente en todos los casos con su jurisprudencia anterior (especialmente por lo que se refiere a la técnica interpretativa de las sentencias conforme), ni procede (salvo excepciones, como es la del caso relativo a la función constitucional de los Estatutos de Autonomía) a analizar toda una serie de categorías dogmáticas que habían sido avaladas anteriormente por la doctrina y la propia jurisprudencia, especialmente en la Sentencia 247/2007, de 12 de diciembre.

siderarse como contrapuesto a la Nación española. Asimismo, defiende la regulación estatutaria de los derechos históricos, la cual, a su juicio, no plantea ninguna duda de constitucionalidad. Y también se refiere brevemente a otras cuestiones como el poder judicial, la financiación y las competencias.

12 Cfr. De Esteban, J., «Reflexiones en torno al voto particular de Javier Delgado», El Cronista, no 15 , págs. 12 ss.

13 Nos remitimos, en tal sentido, a lo expuesto extensamente en Tur Ausina, R., Álvarez Conde, E., Las consecuencias jurídicas... cit., especialmente las págs. 12 y 65 ss. 
Frente a este planteamiento de la posición mayoritaria, los votos particulares contienen, en líneas generales y con independencia de la postura que cada uno mantenga, una mayor fundamentación jurídica — lo cual no es extraño en la dinámica de las resoluciones judiciales que contienen votos particulares-, construyendo incluso algunas categorías dogmáticas, como es el caso de la sentencia oculta de Jorge Rodríguez-Zapata, y la teoría de la competencia conjunta para delimitar el contenido de los Estatutos de $\mathrm{Au}-$ tonomía según expone Javier Delgado, o tratando de oponerse con fundamentación jurídica solvente a los planteamientos de la mayoría, como es el supuesto de la técnica de las interpretaciones conforme a la Constitución llevada a cabo por el Tribunal y que puede resumirse ahora, en general, a través de la idea de que el Tribunal llega a hacerle decir al legislador estatutario lo que éste no quiso decir.

Retomando ideas anteriores, parece obvio que el Tribunal Constitucional que cierra el sistema judicial desde el plano de las garantías constitucionales, esté especialmente vinculado por su propia doctrina. En tal sentido, suele afirmarse que una situación como la expuesta, con una resolución que cuenta con un importante número de votos particulares y que evidencia un Tribunal muy dividido, puede debilitar la fuerza del precedente constitucional, ya no sólo frente a otros operadores jurídicos, sino fundamentalmente desde lo que en el derecho anglosajón se denominaría el «stare decisis horizontal», es decir, frente al propio Tribunal ante resoluciones futuras ${ }^{14}$.

$\mathrm{Al}$ respecto, parece que el Tribunal haya decidido adoptar una «nueva estrategia» a través de la búsqueda de una «opinión única» en torno a esta cuestión, en la posterior Sentencia 137/2010, de 16 de diciembre de 2010, que resolvió el recurso de inconstitucionalidad interpuesto por el Defensor del Pueblo contra el Estatuto de Autonomía de Cataluña ${ }^{15}$. En esta resolución no hay, paradójicamente, ningún voto particular cuando prácticamente un bueno número de cuestiones coincidentes generaron agudas controversias en la Sentencia 31/2010. Para ello se sigue lo que puede ser calificado a priori como una «técnica insólita» en la jurisdicción constitucional española, pues en el antecedente de hecho número 23 se establece explícitamente la votación de los Magistrados por distintos bloques: es decir, señalándose qué ha votado cada Magistrado según los diversos apartados que conforman el fallo de la sentencia, en lo que constituye un auténtico sustitutivo de verdaderos votos particulares ${ }^{16}$. Se produce de este modo, una situación un tanto anómala, pues los Magistrados que votan en contra y, en consecuencia, evidencian claramente su disconformidad con el resultado, renuncian a justificar su discrepancia a través de lo que es el instrumento natural para ello: la redacción de un voto particular, aunque sea para contenerse en el mismo una remisión a votos particulares anteriores, lo que en el presente caso ni siquiera ocurre. Intuimos que, si bien los Magistrados discrepantes parece que se ven obligados a priori a mostrar su coherencia con la resolución an-

14 Magaloni Kerpel A. L., El precedente judicial... cit., pág. 54.

15 Sin perjuicio de un estudio más detenido de la sentencia parece que frente a las incongruencias y debilidades de la primera, la segunda sin dejar de decir aunque sea sólo por remisión a la primera, exactamente lo mismo, presenta sin embargo algún elemento novedoso que puede permitir calificarla, sin ningún sentido peyorativo, como una sentencia tramposa.

16 La revelación de los votos de los Magistrados por el propio Tribunal Constitucional es un hecho novedoso en el funcionamiento de aquél. Sólo en la propia Sentencia 31/2010 el Magistrado Rodríguez Arribas revelaba en su voto particular, precisamente a propuesta suya, la votación por bloques de dicha resolución. 
terior para seguir expresando su disconformidad en el momento de la votación, la práctica a que venimos refiriéndonos puede obedecer, salvo un estudio más detenido de la Sentencia 137/21010, que no es el caso, a que ésta difiere en ciertos aspectos de cierta relevancia de su antecesora — la 31/2010_, como por ejemplo en que ahora toda la fundamentación se lleva al fallo.

Argumento que no resulta incompatible con otras evidencias derivadas de tal práctica, recordando al respecto cómo en el sistema norteamericano, ante situaciones políticas especialmente complejas y tensas, la Supreme Court liderada entonces por el juez Marshall, buscó a principios del S. XIX cohesionar al Tribunal en torno a una única opinión. Esta acción se llevó a cabo, no obstante, no sólo erradicando la técnica del voto particular, sino impidiendo en definitiva conocer cualquier tipo de discrepancia en el seno de aquél. En el fondo, se trataba de fortalecer al Tribunal mostrando su firmeza a través de un pronunciamiento sin fisuras, con el objetivo último de incrementar su peso institucional y su respetabilidad ${ }^{17}$. Una imagen que parece se pone en evidencia —al margen las motivaciones de sus miembros_, precisamente, en la Sentencia 137/2010, ante un Tribunal condicionado y debilitado de facto por factores tanto externos como internos ${ }^{18}$.

Todas las consideraciones efectuadas no empañan, no obstante, que esta técnica seguida por el Tribunal en la Sentencia 137/2010 es en sí misma —y en cierta forma-, una contradicción en sus propios términos. Así, se constata en primer lugar, que sólo está la opinión del Tribunal, sin opiniones concurrentes o disidentes añadidas, pero que simultáneamente hay ciertos Magistrados que están de acuerdo con el argumento — pues no expresan argumentación distinta en votos redactados al efecto, por lo que tácitamente aceptarían la única fundamentación expresada en los distintos fundamentos jurídicos de la sentencia - pero no con el resultado, por lo que viene a crearse una tercera categoría imposible. Una nueva categoría o unos «pseudovotos» diferenciados de los concurrentes y de los disidentes, derivados del hecho de que aún habiendo una única opinión del Tribunal, ésta no pertenece a todos los que lo integran porque así se manifiesta expresamente.

Y es que parece que con este tipo de prácticas la crítica «schmittiana» cobra todo su sentido, contribuyendo así a las dudas de politización del Tribunal ${ }^{19}$. El sometimiento a votación de cuestiones constitucionales, con formación de mayorías y minorías perfectamente identificadas por los propios miembros del Tribunal pero con una única opinión de la institución, pone en evidencia la existencia de una serie de desacuerdos a los que falta - y de ahí el sentido del voto particular — la fundamentación jurídica que está en la base de la discrepancia, poniendo en evidencia que simplemente no se está votando a fa-

17 Vid. en tal sentido, Zobell, K., «Division of Opinion in the Supreme Court: A History of Judicial Disintegration», Cornell Law Quaterly, Vol. 44, 1959, págs. 186 ss.

18 Piénsese, al respecto, ya no sólo en las presiones al Tribunal respecto a la emisión de la Sentencia 31/2010, sino también en las renovaciones pendientes y la larga interinidad de algunos Magistrados, o en las modificaciones que, al respecto, se han tenido que forzar para evitar la coincidencia en el mandato de dos tercios de los Magistrados del Alto Tribunal, por citar algunos aspectos. Vid. en tal sentido, la reforma de la Ley Orgánica del Tribunal Constitucional por Ley Orgánica 8/2010, de 4 de noviembre.

19 Así, recuérdese que Schmitt alertaba del difícil —o en realidad imposible — deslinde entre política y jurisdicción en el seno del Tribunal Constitucional. Cfr. al respecto el agudo enfrentamiento Kelsen-Schmitt, en Schmitt, C., Kelsen, H., La polémica Schmitt/Kelsen sobre la justicia constitucional. El defensor de la Constitución versus ¿Quién debe ser el defensor de la Constitución?, Estudio Preliminar de Giorgio Lombardi, Madrid, 2009. 
vor del criterio de la mayoría. Desde el momento en que no se expone la argumentación jurídica de quien «explícitamente» dice votar en contra del parecer mayoritario del Tribunal, el perfil técnico de éste se resiente, dando paso a estrategias más propias del enfrentamiento político, perfectamente legítimas sin embargo, en otros ámbitos ${ }^{20}$. Así, a la manifestación declarada del voto en contra de un Magistrado ha de acompañarle, por naturaleza, la fundamentación técnica, de tal forma que si aquél toma abiertamente la decisión de apartarse del criterio de la mayoría lo ha de hacer con una opinión alternativa. Si estas premisas no se cumplen entonces el Tribunal deja de ser Tribunal para convertirse en una Asamblea, ya que la fuerza de aquél —y esto afecta también a cada uno de los Magistrados que se identifican en su discrepancia-, está en las razones jurídicas.

Y es que la cuestión no es que hayan votado en contra ciertos Magistrados pues, de hecho, en los órganos judiciales colegiados las sentencias se votan por mayorías y así lo explicita el propio art. 90.1 LOTC, sino la circunstancia misma de que la propia sentencia revele el voto de cada uno de sus miembros. Precisamente, de acuerdo con las consideraciones expuestas, los Magistrados que discrepan y que también, individualmente considerados, se integran en la dinámica del Tribunal, no pueden convertirse en un contrapoder político — como tampoco lo es el propio Tribunal—, debiendo igualmente sujetarse a las formas y a los procedimientos de éste, acordes tanto al proceso judicial ${ }^{21}$ como a la propia naturaleza de esta institución.

20 Son argumentos de teoría general que conviene no perder de vista. Piénsese, al respecto, en las palabras de Hamilton cuando en uno de los artículos de El Federalista afirmaba lo siguiente: «Quien considere con atención los distintos departamentos del poder, percibirá que en un gobierno en que se encuentren separados, el judicial, debido a la naturaleza de sus funciones, será siempre el menos peligroso para los derechos políticos de la Constitución, porque su situación le permitirá estorbarlos o perjudicarlos en menor grado que los otros poderes. El ejecutivo no sólo dispensa los honores, sino que posee la fuerza militar de la comunidad. El legislativo no sólo dispone de la bolsa, sino que dicta las reglas que han de regular los derechos y los deberes de todos los ciudadanos. El judicial, en cambio, no influye ni sobre las armas ni sobre el tesoro; no dirige la riqueza ni la fuerza de la sociedad, y no puede tomar ninguna resolución activa. Puede decirse, con verdad, que no posee fuerza ni voluntad, sino únicamente discernimiento, y que ha de apoyarse, en definitiva, en la ayuda del ejecutivo hasta para que tengan eficacia sus fallos». Cfr. Hamilton, A., Madison, J., Jay J., El Federalista, México, 1994, art. LXXVIII, pág. 330. Más recientemente, Zagrebelsky señalaba que «(...), los jueces no están ligados a la última novedad, los transmisores sí. La razón de ser del juez es el derecho, es decir, algo separado de la crudeza de la vida y de la inmediatez de los hechos, y de lo que ellos llevan en sí de tosco, ocasional, arbitrario y prepotente. El derecho constitucional, en cuanto derecho, es sutileza, estabilidad, ponderación y equilibrio entre los factores principales de la vida social y política. Para ser así, no puede fundarse sobre la fuerza contingente, la que pretende prevalecer aquí y ahora por el único hecho de existir. El sentido del derecho y de la Constitución radica en lo contrario: impedir su descarnado predominio». Zagrebelsky, G., Principios y votos. El Tribunal Constitucional y la política, Madrid, 2008, pág. 98.

21 El art. 80 LOTC dispone la aplicación con carácter supletorio de la Ley Orgánica del Poder Judicial en diversos aspectos entre los que se cita la deliberación y votación. Y en particular, el art. 260 LOPJ es rotundo al efecto, disponiendo que «1. Todo el que tome parte en la votación de una sentencia o auto definitivo firmará lo acordado, aunque bubiere disentido de la mayoría; pero podrá, en este caso, anunciándolo en el momento de la votación o en el de la firma, formular voto particular, en forma de sentencia, en la que podrán aceptarse, por remisión, los puntos de becho y fundamentos de derecho de la dictada por el tribunal con los que estuviere conforme». 


\section{EL CONTENIDO DE LOS VOTOS PARTICULARES}

\section{A) Planteamiento}

El contenido de los votos particulares es susceptible de una distinción entre los aspectos generales de la sentencia, en los cuales se producen grandes coincidencias entre los mismos, y los aspectos temáticos del Estatuto, donde junto a importantes coincidencias, hay también alguna discrepancia, pues no todos ellos abordan la totalidad de las cuestiones planteadas ni, cuando lo hacen, mantienen siempre las mismas posiciones. En líneas generales es posible partir de las siguientes premisas:

1) Todos los votos particulares coinciden en que la sentencia debería haber contenido más declaraciones de inconstitucionalidad. Algunos incluso las cuantifican y otros (en particular, el voto particular de Jorge Rodríguez-Zapata), entienden que estamos ante un «vicio colosal de incompetencia», razón por la cual el Tribunal no debió pronunciarse sobre el contenido del Estatuto, declarándolo todo él inconstitucional ${ }^{22}$. En líneas generales entienden que muchas de las interpretaciones conformes con la Constitución deberían ser, en realidad, auténticas declaraciones de inconstitucionalidad, evitándose, de este modo, las inseguridades jurídicas que implican el uso abusivo de aquellas. Pero ninguno de los votos particulares cuestiona las declaraciones de inconstitucionalidad apreciadas por la mayoría, que se convierten, de esta forma, en declaraciones de inconstitucionalidad unánimes; si bien unos votos las defienden expresamente y otros no las mencionan. A modo de ejemplo, resulta curioso que ningún voto particular llegue a realizar consideración alguna, seria y fundamentada, sobre la inconstitucionalidad del dictamen vinculante del Consejo de Garantías Estatutarias.

2) También todos los votos particulares critican, aunque con distinta fundamentación, el abuso de las sentencias interpretativas, aunque no todos ellos analizan las consecuencias jurídicas que de ello pueden derivarse.

3) Igualmente existe coincidencia en que el fallo no es expresión de la argumentación de la sentencia, pues no se llevan a aquél todas las interpretaciones conformes, que simplemente permanecen a lo largo de los fundamentos jurídicos.

22 Para este magistrado el Estatuto de Autonomía de Cataluña «se subroga en el papel del legislador constituyente y modifica la Constitución sin seguir los procedimientos arbitrados para su reforma; incurre en un vicio colosal de incompetencia que subvierte la división del poder entre el Estado y las Comunidades Autónomas en todos los ámbitos; lesiona la igualdad de todos los españoles en sus derechos, en especial en el derecho, vinculado a la dignidad humana, de que pueden usar en España la lengua española oficial del Estado; colapsa, en fin, el sistema constitucional de fuentes del Derecho y, con él, el funcionamiento mismo del Estado». Y a continuación añade: «El Estatuto de Autonomía de Cataluña incurre en un vicio colosal de inconstitucionalidad formal por incompetencia en un sinfín de preceptos, que irrumpen en materias reservadas constitucionalmente a la Constitución y a las leyes estatales y autonómicas». Los temas afectados son, en particular, el régimen local, el poder judicial, el sistema competencial, y el sistema de financiación. Y añade: «La regulación es inadmisible y no sólo produce una restricción ilegítima e irreversible de la potestad legislativa del Estado (blindaje ad extra) sino también de las potestades legislativas del legislador autonómico (blindaje ad intra) (...). Entiendo así que el nuevo Estatuto de Autonomía de Cataluña es contrario a la Constitución Española en su concepción técnica esencial por la que blinda las competencias estatales y entorpece el ejercicio democrático de las autonómicas, modifica la Constitución Española y convierte en letra muerta treinta años de jurisprudencia constitucional». 
4) Y finalmente, las argumentaciones de los votos particulares no siempre coinciden entre sí, lo cual explica que no haya un único voto particular sino cuatro. Sin embargo, en lo que sí se produce una gran coincidencia es en las declaraciones de inconstitucionalidad añadidas a las declaradas por la sentencia. E incluso hay votos particulares que coinciden en número de preceptos que deberían haber sido declarados inconstitucionales.

\section{B) La posición del propio Tribunal Constitucional}

Lógicamente, el recurso presentado contra el Estatuto de Autonomía de Cataluña no cuestionaba la posición del Tribunal Constitucional en orden a su enjuiciamiento, no pudiéndose decir lo mismo en relación con las alegaciones realizadas por las partes, que intentaron hasta el último momento impedir un pronunciamiento por parte del Tribunal, lo que se ve reflejado en los propios antecedentes de hecho de la sentencia ${ }^{23}$. Sin embargo, la relevancia de la cuestión enjuiciada (prácticamente todo un Estatuto de Autonomía se sometía por vez primera al control del Tribunal) y, de forma especial, la solución adoptada por la doctrina mayoritaria, hace que los cuatro votos particulares aborden esta problemática a través de las siguientes cuestiones.

1. La posición del Tribunal Constitucional en relación con los demás órganos constitucionales del Estado

No parece un despropósito señalar que la STC 31/2010, además de no resolver todas las cuestiones inherentes a nuestro modelo autonómico, ha planteado otras nuevas que afectan seriamente al modelo de justicia constitucional. Un modelo que, además, puede verse afectado también por las reformas realizadas en la LOTC. Así, en primer lugar, la llevada a cabo mediante la LO 8/2010 que prevé que se les reste a los Magistrados entrantes el tiempo de retraso en la renovación de los miembros del Tribunal (lo que implica en estos momentos la reducción a seis años del mandato de los Magistrados elegidos por el Senado), y cuya inconstitucionalidad no parece admitir ninguna duda. Y por otra parte, las modificaciones aún pendientes de realización, como la proposición de ley de reforma de la LOTC, admitida a tramite por el Senado en fecha 1 de junio de $2010^{24}$, en la cual se altera la naturaleza de los Estatutos de Autonomía, con la evidente intención de que no puedan ser declarados inconstitucionales, lo que tiene lugar desde el mas elemental desconocimiento de la teoría de la argumentación jurídica al privar al Tribunal de la función de hacer interpretaciones de los preceptos estatutarios. En esta cuestión, los votos particulares presentan una misma línea argumental, aunque con diferentes razonamientos.

23 Además de las recusaciones de los magistrados, y el fallecimiento de uno de ellos, cfr. el antecedente de hecho $\mathrm{n}^{\circ} 2$ de la STC 31/2010, donde se exponen los diversos avatares a que se vio sometido el Tribunal Constitucional hasta el último momento, con la finalidad de evitar un pronunciamiento del mismo.

24 BOCG n ${ }^{\circ}$ B-253-1, de 4 de junio de 2010. 
Así, para Vicente CONDE, la condición del Tribunal Constitucional como «un Tribunal de Derecho», únicamente sometido a la Constitución y a su Ley Orgánica, no le atribuye, en su condición de intérprete supremo, «un espacio de disponibilidad de la norma sometida a su juicio», ni le permite reconfigurarla, «sino que simplemente marca la jerarquía de sus juicios respecto del resto de los demás posibles intérpretes de la Constitución», razón por la cual el Tribunal no debe interferir en la dinámica política, lo que podría producirse si no ejerce su función de control de constitucionalidad de las leyes. Y ello porque al Tribunal no le corresponde «una potestad de creación de la ley» ni, por supuesto, de creación de un precepto estatutario.

Por su parte, Javier Delgado sigue la línea argumental anterior, aunque quizás con menor énfasis, para señalar que la sentencia se aparta de la función estrictamente jurisdiccional que corresponde al Tribunal, pues crea «unas normas nuevas invadiendo el campo funcional del legislador».

Jorge Rodríguez Zapata es, quizá, el que más planteamientos generales realiza, tratando de fundamentar con ello la inconstitucionalidad global del Estatuto. A este respecto, y tras señalar los intentos de reforma de la LOTC para limitar las posibilidades de control de los Estatutos de Autonomía, mantiene su tesis, expresada ya en otros votos particulares anteriores, de que nos encontramos ante una reforma encubierta de la Constitución $^{25}$. Por otro lado, tras recordar que se invoca poco la jurisprudencia anterior y que la doctrina de la STC 247/2007 es «precedente de la actual» señala que «sólo una vinculación clara y visible a los propios precedentes asegura que la Constitución no sea lo que una mayoría coyuntural de Magistrados del Tribunal Constitucional diga que es. Son necesarias mayorías muy amplias y una fundamentación sólida y convincente, para cambiar precedentes antiguos y estables». Así pues, el Tribunal abdica de su misión esencial de garantizar la superioridad formal de la Constitución, produciéndose «un daño a sí mismo y al sistema constitucional de fuentes del Derecho del que tardará años en sanar», y no proporcionando respuestas aceptables a los problemas planteados.

\section{El significado de las sentencias interpretativas conforme con la Constitución}

Todos los votos particulares admiten la legitimidad de las interpretaciones conforme a la Constitución, recordando incluso los límites establecidos por la jurisprudencia constitucional; pero entienden que la misma no puede consistir en una reconstrucción del mandato normativo enjuiciado, haciéndole decir lo que no dice ni quiso nunca decir. En este caso las argumentaciones de los votos particulares coinciden sustancialmente.

Así, para Vicente CONDE «Las interpretaciones conformes, se fundamentan en el principio de conservación de la ley al servicio del principio democrático, pero no permiten reconfigurar la misma, recreándola, pues eso es invadir la potestad legislativa». La

25 El voto particular, partiendo del principio de que nuestra Constitución «organiza y preside su propia muerte», lo cual es cierto, destaca la rigidez de la misma, la cual «es insuficiente porque todas las leyes tienen una fuerza normativa irresistible. Si una ley vulnera la Constitución, sus normas, aun siendo inconstitucionales, se impondrán a todos y la supremacía formal de la Constitución devendrá una teoría inoperante en la práctica». De ahí la importancia de que la jurisdicción constitucional cumpla fielmente con su función. 
función jurisdiccional no es «una función de creación de la norma enjuiciada». «Salvar la constitucionalidad de una ley recurrida, negando lo que la misma dice, sobre la base de hacerla decir lo que no dice (...) es un modo de abdicación de la función jurisdiccional». Y ello, porque el Tribunal no puede arrogarse la potestad de creación de la ley ${ }^{26}$, ni utilizar, como técnica alternativa a la declaración de inconstitucionalidad, una interpretación conforme lesiva del principio de seguridad jurídica.

Por su parte, Javier Delgado señala que se salva la constitucionalidad de muchos preceptos, pero se les atribuye un sentido diferente y se les despoja de toda virtualidad jurídica. El Tribunal, al proceder a una nueva redacción de no pocos aspectos del Estatuto, se aleja de lo que prescribe la CE: «No declara la inconstitucionalidad de preceptos estatutarios que, en mi opinión, son claramente inconstitucionales, atribuyéndoles un sentido distinto al que deriva de su texto, con lo que se crea una norma nueva, cometido propio del legislador absolutamente ajeno a la función constitucional de este Tribunal» ${ }^{27}$. Y ello porque tanto el art. 9.1 como el art. 9.3 CE suponen que «las leyes que vulneran el modo de convivencia que traza la Constitución resulten radicalmente nulas y así ha de declararlo expresamente este Tribunal, salvo en casos rigurosamente excepcionales cuya justificación debe quedar perfectamente explicitada en la sentencia». La interpretación conforme es una posibilidad legítima, siempre que la norma admita realmente un entendimiento, pero no puede usurpar el terreno del poder legislativo, haciendo que preceptos absolutamente claros y diáfanos deban ser entendidos como dice la sentencia. Y añade: «Una sentencia puede calificarse de interpretativa, en el sentido estricto de esta expresión, cuando excluye una cierta interpretación por inconstitucional o cuando impone otra por entender que un determinado texto no es inconstitucional si se entiende de una determinada manera». Y recuerda, poniendo como ejemplo determinados preceptos estatutarios, que el Tribunal ha actuado como un órgano legislativo, despojando a los mismos de su sentido normativo, pues «pasan a ser un mero conjunto de pretensiones, propósitos, sugerencias o resúmenes de jurisprudencia» ${ }^{28}$.

26 Incluso sostiene que la potestad de interpretación conforme debe ser más restringida en el caso de los Estatutos de Autonomía, precisamente por la función constitucional que cumplen. «Si no cabe en general la recreación de la Ley por el Tribunal Constitucional, menos creo que pueda caber tal recreación cuando de un Estatuto de Autonomía se trata». Lo contrario sería inmiscuirse como árbitro de opciones políticas, función esta que no corresponde a un Tribunal Constitucional. Este Magistrado, al igual que Javier Delgado, propone la declaración de inconstitucionalidad de una cincuentena más de preceptos estatutarios.

27 El propio Magistrado enumera buena parte de los preceptos estatutarios en los cuales se crea un nuevo mandato. Así considera que se produce, entre otros, en el párrafo décimo del Preámbulo, y en los arts. 5 , $6.1,6.2,138$, y 174.3. Asimismo, considera que otros preceptos estatutarios aparecen privados de cualquier sentido normativo: arts. 33.5, 102.3, y todos aquellos donde aparece la cláusula «en todo caso», especialmente en los preceptos que regulan el sistema de delimitación competencial. Con ello, señala el Magistrado, «se viene a dar tierra a aquella extraña figura de la inconstitucionalidad, sin nulidad, pero con ineficacia que aparece en la STC 247/2007, de 12 de diciembre».

28 A este respecto, el Magistrado recuerda toda la jurisprudencia anterior sobre las sentencias interpretativas y los límites establecidos en ella (SSTC 11/1981, 2271985, 45/1989, 222/1992, 34/1993, 96/1996, 235/1995, 194/2000, 184/2003, 24/2004, 138/2005, 235/2007 y 238/2007), señalando que el Tribunal «se aleja ostensiblemente de lo que precisamente para él prescribe nuestra Norma suprema: no declara la inconstitucionalidad de preceptos estatutarios que, en mi opinión, son claramente inconstitucionales, atribuyéndoles un sentido distinto al que deriva de su texto, con lo que se crea una norma nueva, cometido propio del legislador absolutamente ajeno a la función constitucional de este Tribunal (...). En esta sentencia el Tribunal ha 
Por su parte, Jorge RODRíGUEZ-ZAPATA considera que la interpretación conforme es una posibilidad legítima siempre que la norma admita realmente un entendimiento, pero sin que aquella pueda usurpar el terreno del poder legislativo, tal y como ha sucedido en el presente caso. En este sentido, afirma lo siguiente: «Una sentencia puede calificarse de interpretativa, en el sentido estricto de esta expresión, cuando excluye una cierta interpretación por inconstitucional o cuando impone otra por entender que un determinado texto no es inconstitucional si se entiende de una determinada manera» ${ }^{29}$. Las sentencias interpretativas tienen sus límites, que han sido ya delimitados por nuestra jurisprudencia y que, ahora, la sentencia parece olvidar. A este respecto, pone toda una serie de ejemplos de preceptos estatutarios afectados, que coinciden sustancialmente con los anteriores votos. Y a continuación, explicita argumentalmente que nos encontramos en presencia de una sentencia interpretativa de rechazo, pues «el rechazo de una cuestión suele incluir sutilmente una estimación», la cual, al pretender evitar las declaraciones de inconstitucionalidad, se sitúa en un terreno resbaladizo. Por otro lado, señala que no están todas las inconstitucionalidades, que deberían ascender a una cincuentena más de artículos, ni tampoco son todas las inconstitucionalidades que están, sin que la interpretación conforme pueda considerarse un «arreglotodo» ni un «desmóntalotodo». Y es que el Tribunal debe actuar con claridad y no hacer recomendaciones o sugerencias ${ }^{30}$.

Finalmente, Ramón Rodríguez Arribas, que fue quien solicitó la votación por bloques, a tenor de lo establecido en el art. 254 LOPJ —aplicable por remisión del art. 80 LOTC - considera insuficientes las declaraciones de inconstitucionalidad (que debieron afectar a 27 preceptos), y las interpretaciones conformes (a las cuales se debieron añadir otras diez), manteniendo, de este modo, una posición mas próxima a la mayoría que la sostenida por otros votos particulares. Asimismo, destaca que dichas interpretaciones no se recogen en el fallo, como se aceptó en una de las ponencias mayoritariamente, ni en un fundamento jurídico último y conclusivo, al que debería referirse el propio fallo, y como se aceptó con práctica unanimidad en otra de las ponencias. El Magistrado señala que las mencionadas interpretaciones están desperdigadas entre cientos de folios, «situación que dificulta la labor del intérprete y (...) la información de los ciudadanos». Y al propio tiempo, entiende que, al estar en el fallo, ello «equivale a una declaración de estimación parcial de la parte correspondiente del recurso, al declarar que no son incons-

operado no como lo que es — un órgano jurisdiccional — sino como lo que no es — un órgano legislativo- , pues crea un Estatuto nuevo».

29 Y añade a continuación: «La decisión de un Tribunal Constitucional debe ser siempre, en cambio, una expresión vinculante de voluntad. Cuando desestima un recurso confirma — quiérase o no— la voluntad de la ley expresada en la norma jurídica que se controla. Por ello, cuando quiere contrarrestar esa voluntad de algún modo, mediante la interpretación, el matiz o la manipulación de una sentencia interpretativa de rechazo, ha de marcar siempre con claridad que es lo que quiere decir y aclarar al decidir si, y en que medida, su interpretación afecta a la fuerza formal del acto legislativo», concluyendo que no encuentra en la sentencia esa precisión en la mayor parte de las «interpretaciones ocultas» que no se llevan al fallo, pues no se explica en qué sentido el Tribunal interpreta la norma y qué interpretaciones expulsa del ordenamiento jurídico.

$30 \mathrm{Y}$ añade lo siguiente: «La sentencia ha logrado articular, en este caso, un fallo muy escueto, en el que no se contienen excesivas declaraciones de inconstitucionalidad ni demasiadas interpretaciones conformes, con una plausible benevolencia hacia el Estatuto de Autonomía de Cataluña». Es decir, para el Magistrado la sentencia tiene el mérito de esconder con admirable habilidad el alcance del fallo, aunque, sin embargo, plantea el problema de sus efectos. 
titucionales siempre que se interpreten en los términos establecidos (...)». Por ello concluye, citando parte de la jurisprudencia constitucional al caso, que tienen eficacia erga omnes y que de no ser atendido tal mandato «conducirá a la inconstitucionalidad de su aplicación». Asimismo, coincide con los demás Magistrados en los límites de las interpretaciones conformes, pues éstas no pueden suplantar al legislador, ni reconstruir la norma, ni incluir otros preceptos o desarrollos normativos. Ahora bien, su discrepancia «no es tanto por lo que se dice sino mas bien por lo que omite, y por aquellas declaraciones y fundamentaciones que considero insuficientes, ambiguas o erróneas» ${ }^{31}$.

\section{Las consecuencias jurídicas de la actuación de la mayoría}

Todos los votos particulares, unos con mayor énfasis que otros y como ya anticipábamos, están de acuerdo en que la abusiva utilización de las interpretaciones conforme, máxime cuando no todas ellas se llevan al fallo, produce una inseguridad jurídica que afecta tanto a los diferentes operadores jurídicos como a los propios ciudadanos.

En este sentido, Vicente Conde señala que la técnica de la interpretación conforme, en cuanto «alternativa a la pura declaración de constitucionalidad o inconstitucionalidad, no puede caer en el riesgo de inseguridad jurídica (...) dejando márgenes abiertos para una eventual interpretación de la interpretación». La ley tiene como destinatarios a los ciudadanos y su interpretación debe ser inteligible para ellos, pues una técnica contraria en absoluto serviría para la potenciación de la auctoritas del Tribunal, ni para la confianza de los ciudadanos en su Constitución. Y en esta lógica manifiesta que la sentencia «rehace el Estatuto enjuiciado en puntos nucleares del mismo, transformándolo en otro, para salvar su constitucionalidad». Y es que es posible afirmar a la luz de dichas opiniones que el principio de conservación de la norma, utilizado por todos los Tribunales constitucionales, y al cual sirve la técnica de la interpretación conforme, no puede impedir el enjuiciamiento, por parte de éstos, de la conformidad o disconformidad con la Constitución de los Estatutos de Autonomía sometidos a su control, pues este tipo de normas no suponen un cambio significativo en la función enjuiciadora del Tribunal ni exigen una mayor intensidad en la utilización de la interpretación conforme.

Javier Delgado reconoce, en esta línea, que la vía interpretativa resulta oscurecida por la incertidumbre que, en cuanto a su eficacia, acompaña a este tipo de sentencias, frustrándose la finalidad perseguida por la propia Constitución: «En definitiva, el resultado de lo que la sentencia denomina interpretaciones puede desglosarse en dos grandes apartados: en ocasiones, el nuevo sentido atribuido a los preceptos da lugar a un nuevo mandato, pero en otras la norma se vacía de contenido privándola de efectos jurídicos».

31 Pero añade lo siguiente, retomando ideas ya expresadas por otros votos particulares relacionadas con el «mal uso» de las interpretaciones conformes: «De cualquier forma no se debe ignorar que, en los casos en que la interpretación conforme, por su alejamiento o incluso contradicción con el texto legal, pudiera suponer una extralimitación jurisdiccional, porque lo correcto sea la declaración de inconstitucionalidad del precepto cuestionado, los reproches doctrinales o de cualquier otro tipo que pudieran hacerse al Tribunal, no legitiman, ni siquiera justifican o explican, cualquier actitud desobediente a su pronunciamiento». 
Y por su parte, Jorge Rodríguez-Zapata afirma lo siguiente: «Si en el ordenamiento jurídico en que se insertan, y teniendo en cuenta las reglas de interpretación admisibles en Derecho, el contenido o las omisiones de un texto normativo produjeran confusión o dudas que generaran en sus destinatarios una incertidumbre razonablemente insuperable acerca de la conducta exigible para su cumplimiento o sobre la previsibilidad de sus efectos, podría concluirse que la norma infringe el principio de seguridad jurídica». Por tal motivo, puede colegirse de su opinión que la sentencia parece tener un defecto capital de enfoque, sin que dé respuestas aceptables, eludiendo la cuestión formal y eliminando las cuestiones materiales o sustantivas. Y explica el Magistrado en detalle en un argumento que no puede calificarse sino de rotundo: «Los problemas formales (de incompetencia constitucional) deben determinar la inconstitucionalidad de un texto sin necesidad de entrar en un examen material o de fondo del mismo. Cuando existe un vicio formal de incompetencia, y con mayor razón en un Estatuto de Autonomía, no cabe una sentencia interpretativa. Un vicio de incompetencia evidente, consciente y radical, como el del Estatuto de Autonomía de Cataluña, impide a las disposiciones constitucionales estar donde están. En esos casos el remedio no es su interpretación conforme a la Constitución sino la declaración pura y simple de su inconstitucionalidad». De lo contrario, incidiendo en un razonamiento conclusivo común a los distintos votos, se fomenta la confusión jurídica, pues «la seguridad jurídica cede el paso a la interpretación manipulativa», lo que explica afirmando que la sentencia «manipula los preceptos del Estatuto de Autonomía de Cataluña, los modifica y desconoce su sistemática interna hasta convertirlo en un embrollo de normas vacías, paralizadas, futuras o a las que se hace decir lo que no dicen, ni han querido decir». Y añade lo siguiente: «Las leyes se traen ante este Tribunal para que controle su conformidad a la Constitución no para que llame con otros nombres los principios, derechos, competencias y potestades que el legislador ya ha creado. Solo Adán pudo tener ante si todos los animales del campo y todas las aves del cielo para ver como los llamaba, y para que cada ser viviente tuviera el nombre que el les diera (Génesis, 2, 19)».

El Magistrado, finalmente, clarifica lo que en realidad ocurre, advirtiendo de que hay «varias sentencias» en una misma resolución. Junto a una sentencia manifiesta - la que se deduce del fallo- , hay una sentencia oculta, que no aparece en el fallo, aunque «es la que manipula innumerables preceptos esenciales del Estatuto de Autonomía de Cataluña y los aproxima al sentido conforme a la Constitución de otros Estatutos aprobados con posterioridad a él, en un ejercicio desproporcionado de legislación positiva». Y concluye de este modo: «Habrá controversia sobre si esa doctrina escondida tiene plenos efectos frente a todos (art. 161.1 CE a contrario) o si vincula a todos los poderes públicos (art. 38.1 LOTC) las desestimaciones del apartado 4 del fallo, en la medida en que aunque en apariencia desestimen del recurso- quieran ser argumentaciones interpretativas correctoras de muchas disposiciones». Ya por último, nos recuerda que la judicatura y la doctrina italiana han negado eficacia «erga omnes» a las sentencias que esconden entre sus fundamentos interpretaciones que no se llevan al fallo, lo cual ha de plantear importantes problemas a la hora de la ejecución de la sentencia ${ }^{32}$. De cualquier forma, el cú-

32 Aspecto que no obstante, como ya hemos expresado en otro estudio, requiere ser matizado pues, efectivamente, la normativa italiana niega valor doctrinal a las interpretaciones no contenidas en el fallo, prohi- 
mulo de argumentos que expresa el Magistrado produciría, a juicio de éste, una confusión jurídica que supone una vulneración del principio de seguridad jurídica, debido a la manipulación interpretativa efectuada en no pocos preceptos estatutarios. Con ello, concluye, se puede producir «un colapso de nuestro sistema constitucional», pues conduce a una «perfecta fragmentación del Estado».

\section{C) Ámbitos temáticos estatutarios afectados}

\section{Concepto y contenido de los Estatutos de Autonomía}

La STC 31/2010 ha perdido, a nuestro juicio, una colosal oportunidad para sentar las bases de nuestro modelo autonómico, ofreciendo a otros operadores jurídicos, incluido el poder de reforma, los instrumentos adecuados para proceder a una modificación del Título VIII de nuestra Constitución, solución ésta que ahora, y tras la sentencia, nos parece imprescindible. Así como en la STC 247/2007 el Tribunal se explayó, ante la impugnación de un solo precepto estatutario, en consideraciones generales sobre los principios del modelo autonómico, la función constitucional de los Estatutos y las reglas generales del sistema de delimitación competencial, como si de un manual se tratase, ahora sí que estaba obligado a hacer lo propio, pero en sentido contrario a como lo hizo anteriormente. Ahora, con la impugnación de todo un Estatuto de Autonomía, debería haber realizado, con una importante pedagogía constitucional, toda una serie de consideraciones tendentes a cerrar el modelo autonómico en la Constitución.

Sin embargo, el Tribunal ni siquiera responde a todas las argumentaciones de los recurrentes ni de las partes. Únicamente aborda, por pura congruencia procesal, no siempre llevada a sus últimos extremos, cuestiones generales atinentes al concepto y contenido de los Estatutos de Autonomía, acentuando su carácter de ley orgánica, es decir, de norma estatal, y situando en sus justos términos la llamada función constitucional de los Estatutos y su consideración como normas de delimitación competencial. En este sentido, creemos que hay un cierto cambio de orientación jurisprudencial que debería haberse justificado más. Y es que, en lo que al contenido de los Estatutos atañe, parece que la STC 31/2010, sin alterar formalmente sus postulados anteriores, reflejados fundamentalmente en la STC 247/2007, parece representar un cierto cambio de orientación jurisprudencial en relación, al menos, con alguno de los contenidos estatutarios, como es el caso de las declaraciones de derechos.

También esta cuestión de carácter general es abordada, aunque con menor intensidad, por los votos particulares, los cuales no presentan discrepancias especiales entre sí, ni siquiera por lo que al procedimiento de reforma estatutario atañe, pues todos ellos lo consideran, con mayores o menores matices, inconstitucional. En particular, los votos se muestran muy restrictivos con la ampliación de los contenidos estatutarios, entendiendo que se ha producido una violación del principio de reserva estatutaria del art. 147.2 CE. Pero lo importante es señalar que esta línea argumental es propia de la doctrina mayoritaria y parece contagiar a la mantenida por los diferentes votos particulares, pues los

bición a la que no alude, sin embargo, la propia normativa española, teniendo en cuenta además la postura favorable del propio Tribunal en diversas resoluciones. 
mismos renuncian, salvo contadísimas excepciones, y siguiendo los parámetros de la sentencia, a construir categorías dogmáticas alternativas o, en su caso, a analizar las propuestas realizadas por los recurrentes y las partes.

Así, Vicente Conde, posiblemente el voto más expresivo en este tema, entiende que los Estatutos de Autonomía no pueden contener declaraciones de derechos, ni regulaciones referentes a los órganos estatales, ni competencias exclusivas del Estado. Y tampoco pueden invadir las reservas constitucionales a favor de determinadas leyes orgánicas. En cuanto a la reforma estatutaria, ve una contradicción con el art. 147.3 CE, ya que el procedimiento de aprobación por las Cortes no puede ser objeto de regulación por los Estatutos. Y tampoco la Generalitat puede convocar el referéndum, pues dicha convocatoria corresponde al Rey.

Por su parte, Javier Delgado considera que los Estatutos no pueden regular nada que esté fuera de la competencia conjunta exigible para su elaboración y reforma, señalando que la sentencia no es clara en cuanto a la naturaleza y contenido de aquellos, remitiéndose a su voto particular a la STC 247/2007. Únicamente admite, en base a la teoría jurisprudencial de las leyes orgánicas conexas y del significado de las leyes de presupuestos, la existencia de contenidos que guarden una relación directa con la materia reservada, exigiendo que, además, su inclusión haya de resultar precisa y necesaria. Y es que todo lo que no sea objeto de la competencia conjunta Estado/Comunidad Autónoma, no puede ser contenido propiamente estatutario, concluyendo que cuando la Constitución ha previsto un contenido concreto para determinadas leyes, los Estatutos carecen de cualquier competencia al respecto, pues las normas estatutarias no pueden regular materias que queden fuera de su ámbito. Si ello se produce, entonces el Estatuto incurre en una inconstitucionalidad formal, pues desapodera al Estado o la Comunidad Autónoma para regular por sí solos la materia que no estaba en el ámbito de la competencia conjunta. Asimismo, pone de relieve los peligros que encierra la denominada congelación de rango de la norma estatutaria, mostrándose partidario, cuando se produce una extralimitación de los contenidos estatutarios, de que, en este caso, no estemos ante auténticas normas estatutarias sujetas al principio de congelación de rango. Finalmente, en cuanto a la reforma estatutaria, reitera la idea expresada por el anterior Magistrado advirtiendo que los Estatutos no pueden regular el procedimiento ante las Cortes Generales, ni condicionar la voluntad de éstas. E igualmente coincide en que el referéndum debe ser convocado por el Rey, pues el Presidente de la Comunidad Autónoma no tiene atribuida la representación de aquel.

Como habíamos anticipado en líneas anteriores, el Magistrado Jorge Rodríguez-Zapata entiende que el Estatuto presenta «un vicio colosal de incompetencia» que la sentencia no ha asumido, pues no ha declarado la inconstitucionalidad formal del mismo. Inconstitucionalidad formal que excluye, por su propia naturaleza y en consecuencia con tal argumento, cualquier tipo de sentencia interpretativa. Por lo demás, los peligros de «petrificación del ordenamiento jurídico» vuelven a aparecer en los votos, con el consecuente desplazamiento del derecho estatal derivado de la inclusión de cualquier contenido en los Estatutos. Ello le lleva, de este modo, a pronunciarse de forma extensa sobre los límites de la reforma estatutaria, señalando que el EAC desfigura el 147.3 CE, al desconocer «el papel de las Cortes Generales, el del Rey y el de las competencias del Estado». En definitiva, concluye con argumentos contundentes afirmando que la sentencia supone una 
modificación, en sentido federal, del Estado de las Autonomías, pues el Estado ya sólo puede disponer de los procedimientos de reforma constitucional, siendo ése otro rasgo característico de los Estados federales. Para este Magistrado, en suma, el Estatuto ejerce «un poder constituyente prorrogado o sobrevenido» ${ }^{33}$.

Finalmente, Ramón Rodríguez Arribas se centra únicamente en la reforma estatutaria contenida en el Estatuto, especialmente en lo referido al tema del referéndum y a la intervención del Rey, donde mantiene posturas idénticas a las ya expuestas.

\section{Los aspectos identitarios}

El Estatuto de Cataluña, y en general todos los Estatutos de segunda generación, suponen una reafirmación, cuantitativa y cualitativa, de los aspectos identitarios de la respectiva Comunidad Autónoma, que van a verse reflejados en el Preámbulo y en el Título Preliminar del Estatuto. En esta cuestión, las discrepancias de los votos particulares, que no presentan grandes contradicciones entre sí, con la sentencia son radicales, proponiendo la declaración de inconstitucionalidad de otros muchos más preceptos estatutarios, pues entienden que en esta cuestión radica la filosofía política del Estatuto, siendo los preceptos estatutarios cuestionados la expresión jurídica de la misma.

Posiblemente, el voto particular de Vicente Conde sea el más representativo de esta discrepancia radical con la sentencia. Así, empieza criticando la técnica interpretativa de la sentencia, al señalar que «es equívoco por insuficiente afirmar que unos pasajes del Preámbulo pueden carecer de eficacia interpretativa, si no se ha dicho antes de modo terminante que tales pasajes son contrarios a la Constitución. Precisamente porque los pasajes en cuestión son contrarios a la Constitución es por lo que carecen de eficacia jurídica interpretativa. Tal carencia no es adecuado deducirla, saltando sobre esos pasajes, de la interpretación de unos concretos preceptos, y como consecuencia de ella, sino que, a mi juicio, según acabo de sostener, debe ser razonada mediante el examen directo (y anticipado a los preceptos) de los pasajes preambulares cuestionados». Es decir, se interpreta el Preámbulo a través de los preceptos estatutarios cuando debería ser al revés. Una tesis que será seguida por otros Magistrados, como Javier Delgado y Ramón Rodríguez Arribas. Y es que se puede constatar «la existencia de un conjunto global de elementos varios, objetivamente significativos en cuanto potenciales bases jurídicas de sustento de la configuración nacional de Cataluña», pudiendo advertir que la sentencia utiliza una sutileza argumental no exenta de «un cierto carácter evasivo».

A continuación, centrando el tema, señala que la configuración de una nación distinta de la española tiene una singular transcendencia, pues una norma infraconstitucional establece «los elementos normativos de sustento de una tal configuración jurídi-

33 Y concluye afirmando lo siguiente: «Con la consideración aceptada por la mayoría de que no importa que el Estatuto de Autonomía de Cataluña contradiga la Constitución porque es obvio que la Constitución se protege a sí misma — sorprendente tesis esencial de la sentencia de la que discrepo- y que los Estatutos de Autonomía son algo parecido a una manual universitario, que trata de orientar con valor meramente descriptivo en una realidad constitucional indefinida por la CE, dispersa en criterios doctrinales y de categorías in- 
ca», esto es, el Preámbulo y determinados preceptos estatutarios (arts. 2.4. 3, 5, 6, y 8.1.), es decir, casi todo el Título Preliminar. Así pues, nos encontramos ante un mismo fenómeno global, directamente interrelacionado entre sí. Obsérvese, sostiene el Magistrado, que la sentencia no dice que la concepción jurídica de Cataluña como nación es directamente contraria al art. 2, el cual no se refiere a Cataluña y, por tanto, no puede reconocer la realidad nacional de la misma, y cuya primacía debe garantizar el Tribunal Constitucional, aunque sí puede representar un sentimiento o una opción política respetable. Por otro lado, señala que el Estatuto de Autonomía «asigna un fundamento dual al autogobierno de Cataluña, uno de ellos ajeno a la Constitución». Pero además se alude a un ente político unitario (el pueblo catalán) «con aptitud como tal para ser titular de unos derechos cuyo origen es ajeno a la Constitución». Tales premisas no pueden ser más que contestadas cuando afirma que el único titular de la soberanía es el pueblo español «al que, en estrictos términos jurídicos, no puede contraponerse ningún otro pueblo como sujeto unitario titular de derechos de significación fundamentadora de un autogobierno». En definitiva, aunque estemos en presencia de un hecho histórico ello no empece «para la calificación de tal hecho como contrario a la Constitución» ${ }^{34}$.

En otro orden de consideraciones, entiende que el art. 2.4 del Estatuto es inconstitucional y nulo, y que «la sentencia, al no declararlo así, está devaluando el significado normativo del precepto, transformándolo en otro distinto para salvar su validez constitucional». Además, al utilizar la expresión «el marco político» se está aludiendo a la existencia de dos entes de similar entidad política cuando lo cierto es que la Generalitat es Estado, pero no es reconducible al Estado español. Asimismo, considera, en lo que es una línea argumental constante en los votos, que el art. 5 del Estatuto según interpretación de la sentencia, es un ejemplo de cómo se rehace un precepto estatutario, transformándolo en otro: lo que el precepto dice es precisamente lo que la sentencia niega, siendo obvio que el precepto reproduce lo que se dice en el Preámbulo. Finalmente, también considera inconstitucional la regulación estatutaria de la lengua, que entiende como «un instrumento de construcción nacional». A este respecto, señala que el artículo «la» del art. 6.1 del Estatuto sitúa fuera del ámbito de la normalidad el uso posible de otras lenguas, y que al no declararse inconstitucional se produce «una situación de inseguridad jurídica». En cuanto al deber de conocer el catalán, afirma que la sentencia niega el sentido jurídico del precepto, dándole, como ya ocurría con anterioridad con otros artículos, otro diferente al de sus términos literales. Para el Magistrado el Estatuto no es una norma adecuada para imponer deberes a la ciudadanía, mostrándose asimismo contrario a muchos de los derechos lingüísticos estatutorizados ${ }^{35}$.

ciertas (FJ 58, tercer párrafo), se contradicen los principios elementales que acabo de enunciar y el Tribunal abdica de su misión esencial de garantizar la superioridad formal de la CE sobre los Estatutos de Autonomía».

34 A este respecto el Magistrado interpreta adecuadamente la voluntad del legislador estatutario señalando que «el razonamiento de la sentencia, a mi juicio, confunde la eficacia jurídica interpretativa de tales términos, aunque el Tribunal no la hubiera negado de forma taxativa; y porque en el plano del derecho internacional - mucho mas relevante sin duda para los impulsores del texto — es igualmente difícil de imaginar que el fallo del Tribunal pueda privar de potencialidad reivindicativa a una norma de derecho interno que dispone, sin que el Tribunal Constitucional lo haya anulado, que Cataluña es una nación y que tiene símbolos nacionales».

35 Y añade lo siguiente: «Creo que sólo desde la radicalidad de las ideas de Nación y Estado, y en relación con ellas de la de ciudadano del Estado, tiene explicación que en la norma suprema que los configura como tales puedan imponerse deberes básicos a los ciudadanos (extensibles en términos iguales a todos ellos) de la ín- 
Por su parte, Javier Delgado destaca la importancia de los Preámbulos, pues en ellos se «explica, da sentido y sirve de base fundamental para la interpretación de los conceptos, definiciones, principios y normas fundamentales que se contienen en un Estatuto». Y por ello deben ser recurribles. Pero es que, además, la quintaesencia del Estatuto está en el Preámbulo, que tiene su directo reflejo en el Titulo Preliminar. Desde estos planteamientos le resulta posible afirmar, en consecuencia, que se deberían haber declarados inconstitucionales todas las referencias a la nación y expresiones similares que se contienen en el Preámbulo, así como las consecuencias jurídicas que de esta concepción se recogen en el Titulo Preliminar, mostrándose contrario a la técnica que utiliza la sentencia, constantemente reiterada por éste y otros Magistrados, y que hace decir a los preceptos estatutarios lo que realmente no dicen ni quieren decir $^{36}$. Coincidiendo con los argumentos de Vicente Conde, considera igualmente inconstitucional la regulación de la lengua.

Jorge Rodríguez-Zapata también realiza, citando las SSTC 76/1988, 147/2007 y 103/2008, una radical crítica a la regulación de los aspectos identitarios, señalando que «ni nación es un termino extraordinariamente proteico, ni Estado un concepto ambiguo, ni la ciudadanía española un genero con diecisiete especies». Y considerando el Preámbulo, sostiene que en el mismo, examinado por la sentencia de forma aislada y sin una visión de conjunto, se mantienen afirmaciones que irrumpen «en los ámbitos inconfundibles del poder constituyente», utilizando el lenguaje propio de los textos constitucionales. Son estos motivos los que le llevan a proclamar que el fallo no debería haberlo privado sólo de eficacia interpretativa, pues es inconstitucional, máxime si se trata de un Estatuto de Autonomía, donde los Preámbulos sirven de canon de interpretación no sólo del propio Estatuto, «sino de todas las normas del ordenamiento autonómico que dimanan de él, y vinculan a todos los poderes públicos autonómicos». E igualmente, en línea coherente con otros votos particulares, serían inconstitucionales todos los artículos del Título Preliminar que se refieren a la cuestión, representando algunos de ellos una clara opción confederal y desconociendo que en nuestro ordenamiento jurídico el Estado central siempre ostenta una posición de superioridad.

Por su parte, Ramón Rodríguez Arribas mantiene unos planteamientos semejantes a los anteriores, concluyendo que las concepciones mantenidas sobre los aspectos identitarios, aunque pudieran ser «entendidas como aspiraciones políticas de un partido o de un grupo social», son constitucionalmente inadmisibles; consideración ésta que se extiende a los arts. 5 y 8.1 del Estatuto, así como a diferentes derechos lingüísticos.

dole del referido al conocimiento de un idioma; pero, negándose esos elementos de partida (Nación y Estado, y condición de ciudadano diferenciada), y negando el carácter del Estatuto de Autonomía en cuanto Constitución de una Comunidad Autónoma, faltan las bases jurídicas para poder establecer un deber como el que examinamos. En otros términos, y respondiendo al planteamiento de la sentencia al que doy respuesta: creo que la imposición del deber de conocimiento de un idioma no es una opción abierta al legislador estatuyente».

36 En este sentido señala que una vez que la sentencia ha declarado que «la Constitución no reconoce otra nación que la Nación española», debería haber declarado inconstitucionales el art. 8.1, referente a los símbolos nacionales; el art 2.4, cuando señala que los poderes de la Generalitat emanan del pueblo de Cataluña; el art. 5, referente a los derechos históricos del pueblo de Cataluña; el art. 3.1, referente al principio de bilateralidad; el art. 6.1, donde se regula la lengua propia de Cataluña; y diferentes preceptos estatutarios reguladores de los derechos lingüísticos. 


\section{Derechos estatutarios}

Las declaraciones de derechos estatutarias habían sido ya objeto de enjuiciamiento por la STC 247/2007, a la cual estos mismos Magistrados presentaron diversos votos particulares. Ahora, la STC 31/2010, efectúa un ligero cambio de orientación jurisprudencial, a nuestro juicio acertado, en orden a una mayor aceptación de este tipo de declaraciones estatutarias. Los Magistrados discrepantes, consecuentes con su lógica, presentan también votos particulares, en los cuales sostienen la tesis de que se ha excedido el principio de reserva estatutaria. Sin embargo, y según ellos para no reiterar sus argumentos expuestos en sus votos particulares a la STC 247/2007, las consideraciones realizadas en el presente caso son mucho más escuetas y menos argumentadas, con excepción de los llamados derechos lingüísticos, sin que se puedan apreciar contradicciones sustanciales entre las posturas mantenidas.

El Magistrado que más se explaya sobre estas cuestiones es Vicente Conde, para quien los Estatutos de Autonomía no pueden contener declaraciones de derechos, remitiéndose al voto particular que suscribió a la STC 247/2007: «Me parece que carece de rigor jurídico una tesis que, en lo esencial, se resume en la idea de que los que en el texto legal se establecen como derechos no lo son». Asimismo, enjuicia los mandatos estatutarios: cuando en el Estatuto se «establece un determinado mandato normativo, la existencia jurídica como tal de dicho mandato no esta condicionada por la regulación que del mismo pueda, o deba, hacerse en las normas a que se remiten los preceptos en los que se establece», pues «(...) el respeto a esos mandatos viene ya impuesto a las normas a las que el Estatuto se remite, de modo que en los extremos concernidos por dichos mandatos el Estatuto de Autonomía es condición de validez de las normas a las que se remiten». Y ello sin que pueda entenderse al revés, pues las «normas remitidas no son condición de la validez de la norma de remisión, sino que la validez de ésta es condicionante de la de las normas remitidas». Por lo demás, y de nuevo, en los derechos lingüísticos se hace deducir de los preceptos estatutarios lo contrario de lo que dicen: «Lo que no cabe es que el precepto disponga lo que dispone; y en la medida en que lo hace, debe declararse inconstitucional y nulo. Lo que no cabe, es entenderlo de modo contrario a su sentido para salvar su constitucionalidad».

Por su parte, Javier Delgado analiza los principios constitucionales referentes a esta cuestión, concluyendo que el Estatuto supone, por principio, una desigualdad de derechos, no siendo aquél la norma habilitada a tal respecto. Dichos argumentos le llevan a declarar los preceptos que expresamente considera inconstitucionales (arts. 15.1 y 2, art. 20 , art. 21.1 y 2 , art. 37.1 .2 y 3 y art. 38.1).

El resto de votos son más puntuales pues, en primer lugar, Jorge RoDRíGUEZ-ZAPATA se centra únicamente en la materia de los derechos lingüísticos, a los cuales califica de ejemplo evidente de sentencia oculta a la que viene haciendo referencia. Y por su parte, Ramón Rodríguez Arribas se limita a señalar que las consideraciones de la sentencia sobre determinados derechos, como la vida, la educación y la libertad religiosa (arts. 20, 21 y 41.5 EAC), y realizadas como interpretaciones conformes, hubieran debido trasladarse al fallo. 
4. El Poder judicial

La regulación estatutaria del Poder Judicial, tema en el cual la sentencia aprecia un mayor número de inconstitucionalidades, es abordada por los votos particulares, con la excepción del de Jorge Rodríguez-Zapata que apenas se pronuncia sobre el tema. Y lo hacen con planteamientos similares, aunque con razonamientos no siempre idénticos. Quizá en esta cuestión no conviene olvidar, a la hora de entender las discrepancias en esta cuestión, que todos los Magistrados con opiniones minoritarias tienen la condición de Magistrados del Tribunal Supremo y que desde ésta han accedido a la categoría de miembros del Tribunal Constitucional.

A tal efecto, la discrepancia mas radical, pero también el razonamiento más fundamentado, corresponde a Vicente CONDE, para quien estamos ante un tema que no es, propiamente hablando, un contenido de los Estatutos, por lo que a priori existe una violación del principio de reserva de ley orgánica así como sobre el alcance de la LOPJ. Así, el voto empieza criticando la tesis de la STC 247/2007 sobre la distinción entre validez y eficacia de los preceptos estatutarios que invadían la reserva de ley orgánica, en el sentido, como ya expuso en su propio voto particular a la referida sentencia, de que carecían según el Tribunal, de eficacia pero no de invalidez. A este respecto, recuerda que, efectivamente, ahora la sentencia no trae a colación esta doctrina, lo que plantea el problema de si se ha rectificado o no, y señalando que el vaciamiento de muchos preceptos estatutarios le hace sospechar que «los efectos de esa doctrina, por mí rechazada, puedan haber operado implícitamente en la adopción de las decisiones a que llega la sentencia». Asimismo, considera que la sentencia es muy tolerante con los preceptos estatutarios, y que la distinción entre la Administración de Justicia y la Administración de la Administración de Justicia, doctrina jurisprudencial construida por vía de interpretación conforme, no puede conducir a la elaboración de todo un Título: «En una reflexión histórica inmediata creo que el referido salto debiera hacer pensar al Tribunal sobre los resultados a los que conducen a veces a lo largo del tiempo las interpretaciones conformes mediante las que, atenuando el rigor del discurso jurídico, se acepta rebajar la claridad de los límites entre lo que constitucionalmente debe corresponder en todo caso al Estado y lo que pueda corresponder a las Comunidades Autónomas». En cuanto al Consejo de Justicia entiende, poniendo de manifiesto un hecho palpable, que se declara la inconstitucionalidad de un órgano y al mismo tiempo se pretende «salvar la constitucionalidad posible de un órgano diferente, que el Estatuto no ha creado en este caso». En definitiva, estaríamos ante un juicio preventivo de constitucionalidad, tan rechazable como los juicios preventivos de inconstitucionalidad: «En realidad de lo que se trata con tal recurso dialéctico es de salvar determinados contenidos de los artículos siguientes, sobre la base irreal de considerarlos referidos, no al órgano concreto al que el Estatuto de Autonomía de Cataluña los refiere, sino a otro órgano hipotético». El Magistrado señala lo que es obvio pues, una vez declarado inconstitucional el órgano, también lo deben ser todas sus competencias y composición, pues no puede haber competencia sin sujeto ni composición de un órgano sin órgano.

También el voto de Javier Delgado insiste, fundamentalmente y en una línea similar a la anterior, en los Consejos de Justicia, considerando que la sentencia se inventa un nuevo órgano que ya no se inserta en la organización del Consejo General del Poder Judi- 
cial sino en la Generalitat: es un órgano autonómico totalmente falto de apoyo estatutario. Ello le permite afirmar, en consecuencia, que la inconstitucionalidad del art. 97 debe extenderse a los arts. 98 y 99, reguladores de la composición y atribuciones de dicho Consejo.

Finalmente, la posición de Ramón Rodríguez Arribas expresa su sensibilidad con esta cuestión, donde las incoherencias de la sentencia aparecen claras y determinantes, y manifestando su máxima discrepancia con la fundamentación de la mayoría. En relación con el Consejo de Justicia se refiere a los «órganos inexistentes que reaparecen». Y asimismo se muestra contrario a las posibilidades de su regulación por la Ley Orgánica del Poder Judicial que apunta la sentencia, pues no es posible, constitucionalmente hablando, crear Consejos desconcentrados, aunque la sentencia diga que las formulas de desconcentración son constitucionalmente imprescindibles: «Lo más que cabría hacer y ya fuera del Estatuto de Autonomía, sería la creación de un órgano que asumiera exclusivamente las competencias autonómicas sobre la Administración de la Administración de Justicia, pero sin ninguna facultad sobre los jueces y magistrados y sin sustituir a las Salas de Gobierno integradas solo por aquellos».

\section{El régimen local}

El régimen local configurado por el EAC apenas es abordado en los votos particulares a la sentencia. Un tema donde no se produce ninguna declaración de inconstitucionalidad, aunque sí importantes interpretaciones conformes que desvirtúan el sentido y contenido de algunos preceptos estatutarios.

Prácticamente va a ser Vicente Conde el único que presente un auténtico voto particular en esta cuestión. En su opinión el Estatuto hace desaparecer la provincia, por lo que, con ello, «la organización territorial del Estado no tiene continuidad estricta en Cataluña». Por tales motivos, porque la estructura territorial no puede ser discontinua, puede llegar a afirmar que los arts. 90 y 91 son inconstitucionales. Siendo esto así concluye que la interpretación de la sentencia puede ser calificada de «artificiosa y falta de realismo», pues, «la denominación que la Constitución da a unos entes integrantes de su organización estructural supone un elemento de identidad que creo que no admite su cambio por normas infraconstitucionales». Es por tales motivos por los que, de nuevo y ahora en esta cuestión, la sentencia crea inseguridad jurídica en un tema de tanta trascendencia como es la estructura territorial del Estado, al no pronunciarse sobre lo que sea la veguería y dejarlo a lo que diga el legislador de desarrollo.

Se acerca a tal razonamiento, por su parte, Ramón Rodríguez Arribas, quien aprecia la existencia de alguna inconstitucionalidad, señalando que no se puede dejar todo abierto «con una suerte de constitucionalidad condicional, según lo que haga el legislador autonómico».

\section{Las competencias}

El sistema de distribución competencial es analizado por la sentencia con tres declaraciones de inconstitucionalidad, referidas todas ellas a la misma cuestión, y con 
muchas interpretaciones conformes, no todas las cuales se llevan al fallo de la misma. Los votos particulares abordan, no con excesiva extensión, pues parecen entender que el modelo estatutario ha sido totalmente desactivado por la sentencia de la mayoría, el sistema competencial, si bien proponiendo más inconstitucionalidades, especialmente por lo que se refiere a los arts. 110, 111 y 112. De otra parte, presentan algunas discrepancias entre sí.

En efecto, Vicente Conde se muestra contrario a los arts. 110, 111 y 112, al señalar que los tres son inconstitucionales por hacer interpretaciones abstractas de conceptos constitucionales, y por situarse en el lugar que corresponde al Tribunal como intérprete supremo. Asimismo, señala que la sentencia desvirtúa el significado de los preceptos a base de convertirlos en una mera descripción sistematizada de la jurisprudencia, descripción que no es vinculante, sin embargo, para el Tribunal Constitucional. Ahora bien, la no declaración expresa de inconstitucionalidad formal de los referidos preceptos le hace señalar que lo que en otro tiempo fue doctrina se ha convertido ahora en norma legal que, «a menos que se expulsen del ordenamiento jurídico mediante su declaración de inconstitucionalidad y nulidad, no pueden ser desconocidas por el Tribunal con doctrinas no respetuosas con el contenido de dichas normas». Aunque no se dice que no son normas jurídicas, sino sólo descripción sistematizada de la jurisprudencia, «los preceptos sobre los que discurro no son interpretaciones abstractas de conceptos o categorías constitucionales, en cuyo caso serían inconstitucionales, sino definición sistematizadora y globalizada de las funciones comprendidas en las concretas competencias asumidas por la Generalitat en el Estatuto». Son conceptos estatutarios, en definitiva ${ }^{37}$. El Magistrado acepta las tesis de la sentencia sobre el art. 110, comparte la inconstitucionalidad del 111, entiende que la inclusión de la potestad reglamentaria en el art. 112 es inconstitucional, y discrepa de la interpretación conforme del 114. Pero también considera inconstitucionales muchos otros preceptos del reparto de competencias: el alcance de competencia exclusiva, la expresión «en todo caso», la participación en materias de competencia estatal, las competencias en materia de derecho civil, de inmigración, etc., concluyendo que el sistema puede quedar congelado y bloqueado ${ }^{38}$.

37 «Lo que hace la sentencia, a mi juicio, es desvirtuar el significado jurídico ordenador de los preceptos, a base de convertirlos en una mera descripción sistematizada de la jurisprudencia de este Tribunal sobre el sistema de reparto de competencias entre el Estado y las Comunidades Autónomas, que, (si he comprendido bien), concluye negando que esa descripción sistematizada pueda ser vinculante para el Tribunal Constitucional». Y más adelante añade: «En la materia que ahora nos ocupa no puede aceptarse, que lo que fue en su día doctrina de este Tribunal, como tal revisable por él, al transmutarse en norma jurídica de la rigidez que es propia de un Estatuto de Autonomía, el sistema de distribución de competencias pueda quedar bloqueado y alterado, congelado en el Estatuto, sin revisión unilateral posible, y ahora sobre otra base, cual es la de las definiciones de sus arts. 110, 111 y 112 (inexistentes cuando dicha doctrina jurisprudencia se pronunció), lo que sobre bases jurídicas distintas pudo ser un cierto momento de nuestra jurisprudencia».

38 A este respecto, entiende que la reserva de la exclusividad del Estado no puede contraerse sólo al momento de la decisión, «sino que es extensible a todo el espacio lógico del ejercicio de la competencia exclusiva». Y concluye de la siguiente forma: «Cosa diferente es que con plena disponibilidad de su competencia el titular pueda, si así lo considera conveniente, abrir vías de colaboración y de participación de quienes, en su caso, pudieran resultar afectados por su ejercicio; pero eso es distinto de que en un Estatuto de Autonomía, con la rigidez que es propia a tal tipo de fuente del Derecho, respecto de la que no vale la disponibilidad unilateral del Estado sobre su posible modificación, invada el ámbito de la competencia exclusiva del Estado, atribuyendo en 
Por su parte, con argumentos de fondo en parte coincidentes con el anterior Magistrado, Javier Delgado entiende que los arts. 110 a 112 son auténticas normas jurídicas, pues constituyen verdaderos mandatos, y los tres son inconstitucionales a su juicio, ya que la definición de lo que ha de entenderse por competencia, así como las potestades que la integran, está reservada a la Constitución. Por ello, estamos en presencia de preceptos sin virtualidad jurídica alguna, pues ésta únicamente puede predicarse de la propia doctrina del Tribunal y no de los contenidos de estos preceptos estatutarios. Ello le permite criticar la fundamentación de la sentencia en el sentido señalado por ésta de que la regulación estatutaria es para evitar la incertidumbre que puede existir para la «cognoscibilidad y reconocimiento» de la doctrina jurisprudencial, argumento éste que, a su juicio, atenta contra la más elemental de las inteligencias. Finalmente, se muestra contrario a la interpretación dada a la expresión «en todo caso», existente en numerosos preceptos reguladores de las competencias estatutarias ${ }^{39}$.

Aunque con matices diferenciados en la argumentación, también Jorge Rodríguez-Zapata se muestra radicalmente contrario con el sistema del blindaje, entendiendo que «es inadmisible por ello que el Estatuto de Autonomía de Cataluña concrete o precise las materias y competencias que el art. 149.1 CE ha reservado a todo el Estado, obstruya en cualquier forma que el Estado legisle con carácter general en ejercicio de esas competencias o dirija mandatos al Estado y le imponga, incluso, una organización estatal determinada». Sus análisis sobre la técnica del blindaje son exhaustivos, pues sostiene que mediante dicha técnica se produce una auténtica esclerosis del reparto competencial, la petrificación del ordenamiento jurídico y el desplazamiento del derecho estatal. Y a continuación señala que el precio que hace pagar la sentencia por el empleo de tal técnica es el de privar parcialmente de valor vinculante a las normas estatutarias en cuestión, rompiendo todo la coherencia del Estatuto: «QQué ocurre con la fuerza activa o innovadora y fuerza derogatoria del Estatuto de Autonomía de Cataluña, por la que éste se inserta en el ordenamiento jurídico? ¿Sigue vigente en Cataluña el derecho del Estado afectado por un estatuto que contiene, en realidad, una cláusula subrogatoria gigantesca?». En función de todo lo anterior concluye que se producirán consecuencias incalculables en el sistema de fuentes del Derecho, pues «Toda norma incompetente pasaría a evitar su inconstitucionalidad llamando en su auxilio a la norma competente para que dote de fuerza normativa a sus deseos, y sin perjuicio de que con toda o perfecta libertad pueda dejarla, cuando desee, huérfana nuevamente de competencia».

El voto particular de Ramón RoDRíGUEz ARRIBAs parece tener un perfil diverso a los anteriores, pues no se opone frontalmente a las tesis de la mayoría y sólo discrepa en

él ningún tipo de competencia a una Comunidad Autónoma, por muy liviana que pueda ser esa competencia, que en cualquier caso supondría para el Estado, titular de la competencia exclusiva, una limitación que en adelante deberá respetar».

39 Sus conclusiones son rotundas y plenamente acertadas en este ámbito temático: «todos estos preceptos, con esta técnica de despojo de sentido normativo, pasan a ser un conjunto de pretensiones, sugerencias o resúmenes de jurisprudencia. Esta falta de virtualidad jurídica de la norma, siempre anómala, resulta más llamativa cuando el mandato contenido en el precepto estatutario tiene como destinatario único el Estado: el Estatuto es una ley, lo que significa que sus preceptos son normas jurídicas, con toda la fuerza vinculante frente a todos que es propia de la ley, de suerte que si ésta ordena al Estado una determinada actuación (...) el Estado estará obligado a llevarla a cabo»; y ello aunque la sentencia declare que el Estado puede o no cumplir con el mandato con entera, plena y perfecta libertad, evitando así la declaración de inconstitucionalidad. 
algunas materias puntuales y concretas, apreciando inconstitucionalidades nuevas en los arts. $117.3,138,174.3,134,142.2,180$, y 183, entre otros.

\section{Relaciones institucionales}

El ámbito de las relaciones institucionales es analizado por la sentencia en directa relación con el principio de bilateralidad, no efectuando ninguna declaración de inconstitucionalidad - lo que es contestado desde los votos particulares-, aunque sí algunas interpretaciones conformes, no toda las cuales, como ocurre con tantas otras cuestiones, son llevadas al fallo de la sentencia.

Así, Vicente Conde propone, frente a la ausencia de disconformidad con la Constitución por parte de la sentencia, la declaración de numerosas inconstitucionalidades. Pero además entiende que no son contenidos de los Estatutos, y que las remisiones a las leyes no salvan la inconstitucionalidad de los preceptos afectados. De nuevo, como ya se ha denunciado respecto a otros ámbitos, sostiene el Magistrado que la interpretación conforme realizada por la sentencia «llega en ocasiones a extremos inaceptables para mí, pues supone hacerle decir a veces a los preceptos lo contrario de lo que en una lectura respetuosa con su literalidad debe entenderse que dicen». Por ello, y en este sentido, considera inconstitucionales los arts. 174.3, 180, 182, 183, Disposición Adicional Segunda y 187.1 y 2 del Estatuto.

Por su parte, Javier Delgado, como hemos apuntado, considera inconstitucional la regulación del principio de bilateralidad del art. 3.1 del Estatuto, pues es una consecuencia de la configuración de Cataluña como nación, así como la rúbrica «marco político» del título Preliminar. Y también considera inconstitucionales los arts. 174.3, 180 y 183 , pues «en modo alguno le es dado al legislador estatuyente precisar los mecanismos a través de los cuales el Estado ha de hacer efectiva esa cooperación y mediante los que ha de articularse la participación de las Comunidades Autónomas en el ejercicio de las competencias del Estado». Es decir, el Estatuto de Autonomía no es la norma adecuada, ya que el objeto escapa «del preciso ámbito de las competencias conjuntas susceptible de ser regulado por la ley estatuyente».

Jorge Rodríguez-Zapata también retoma ideas anteriores para criticar la configuración de «el marco político» que se hace en el Título Preliminar del Estatuto y la teoría de la posición singular de Cataluña. Y es que entiende desde la base de la argumentación, que nos estamos situando en un sistema de relaciones propias del Derecho internacional, como si de Estados soberanos se tratase, concluyendo que las relaciones entre el todo y la parte no pueden ser detalladas de una forma general y permanente. De este tono crítico participa también Ramón Rodríguez Arribas.

\section{La financiación}

En el tema de la financiación autonómica, la sentencia de la mayoría únicamente aprecia la existencia de dos inconstitucionalidades formales y realiza varias interpretaciones conforme a la Constitución. Y por su parte, los votos particulares, aunque lo con- 
sideran uno de los temas claves del Estatuto, sin embargo apenas se refieren a esta cuestión, aunque aprecian la existencia de muchas inconstitucionalidades.

Para Vicente Conde no es éste un contenido propiamente estatutario, razón por la cual han de primar las reservas a favor de leyes orgánicas. En tal sentido, y tras recordar los límites de la interpretación conforme, entiende que sólo por razones formales, es decir por la invasión del ámbito competencial reservado a la LOFCA, los preceptos estatutarios son inconstitucionales. Sus últimas consideraciones se enmarcan en uno de los hilos conductores argumentales de los votos, pues para el Magistrado la sentencia salva la constitucionalidad de los preceptos convirtiéndolos en otros totalmente diferentes. Así, considera inconstitucionales los arts. 201.3, 204.1 y 4, 205, 206.5, 210, 219.2 y 4 y las disposiciones adicionales séptima, octava, novena y décima.

En análogo sentido se pronuncia Javier Delgado, para quien, citando la jurisprudencia constitucional anterior (a tal efecto, las SSTC 11/1984, 197/1987, 68/1996, 192/2000, 16/2003, 109/2004 y 13/2007), la regulación estatutaria limita la libertad de configuración del legislador estatal, tratando de reducir el protagonismo de la LOFCA, que es la norma delimitadora de las competencias financieras estatales y autonómicas.

Finalmente, el Magistrado Ramón Rodríguez Arribas considera la sentencia insuficiente, pues como avanzábamos aprecia la inconstitucionalidad de otros muchos preceptos estatutarios que enumera conclusivamente: arts. 201.4, 205.1, 106.5, 210 y las disposiciones adicionales tercera, octava, novena y décima.

\section{CONCLUSIONES}

De los cuatro votos particulares analizados es posible establecer, entre otras, las siguientes conclusiones:

Los votos particulares, unas veces manteniendo una misma línea argumentativa y otras, las menos, presentando discrepancias entre sí, presentan una concepción radicalmente distinta de la mantenida por la sentencia.

Resulta significativo que los auténticos votos particulares a la sentencia sean suscritos todos ellos por Magistrados del Tribunal Supremo. No obstante, ello no debe a nuestro juicio ser interpretado como un renacimiento de las tensiones entre la jurisdicción ordinaria y la jurisdicción constitucional, y ni siquiera como expresión de la regulación del poder Judicial en el Estatuto, aunque para alguno de ellos esta cuestión constituya una de las más esenciales discrepancias, sino por la distinta posición que ocupan en relación con otros juristas procedentes de otros ámbitos.

También es posible concluir que se produce una cierta identidad entre las posturas mayoritaria y minoritaria del Tribunal en lo referente a la aceptación por parte de ésta de las declaraciones de inconstitucionalidad y de las interpretaciones conforme llevadas al fallo por aquélla.

No obstante, las diferencias cabría encontrarlas, sin embargo, en la afirmación por los votos de que estas declaraciones de conformidad debieron ser en realidad declaraciones de inconstitucionalidad, las cuales hubieran tenido que extenderse a otros muchos preceptos. Argumento que se conecta con la crítica generalizada realizada por los votos, sobre el deficiente uso realizado por la sentencia, de la técnica de la sentencia interpretativa. 
Por supuesto, entienden que todas las interpretaciones conformes deberían haber figurado en el fallo de la sentencia. Razones de seguridad jurídica son, en resumidas cuentas, la que están en la base de este argumento.

Los votos, con independencia de la posición jurídica en que nos situemos, contienen, en líneas generales, una argumentación jurídica de mayor calidad técnica que la utilizada por la sentencia de la que discrepan.

Finalmente, es difícil de prever, dadas las circunstancias actuales, cuál ha de ser el futuro de esta doctrina minoritaria del Tribunal, pues también resulta imposible predeterminar la permanencia de la posición de la mayoría del mismo. Ello teniendo en cuenta tanto las renovaciones del Tribunal que se están produciendo y tienen que producirse, como la necesidad de un análisis más exhaustivo de la Sentencia 137/2010, aunque intuimos que cierto cambio se atisba, como hemos manifestado en líneas anteriores al constatar la inexistencia de votos particulares a la misma.

Desde consideraciones concluyentes al presente estudio podemos señalar que lo realmente importante es determinar si en el presente caso hubiera sido factible la existencia de una sentencia unánime, aunque con la posible existencia también de votos concurrentes. Realmente, la solución de un caso de tanta envergadura e importancia como el Estatuto de Autonomía de Cataluña hubiera merecido un esfuerzo mayor por parte de los magistrados del Tribunal en orden a encontrar una solución más unánime en torno al mismo. Todo ello pensando, además, que han dispuesto de un plazo de tiempo excesivo para lograr un acuerdo entre las diferentes posiciones, sin dejarse influenciar por elementos y presiones externas y por la propia caducidad del mandato de muchos de ellos. En nuestra opinión ello hubiera sido factible, con todas las dificultades que se quiera, siempre que a) se hubieran aumentado las declaraciones de inconstitucionalidad, que tampoco tendrían que haber afectado a cuestiones absolutamente esenciales; b) se hubiese abandonado la utilización abusiva y en cierta forma forzada de la técnica de las sentencias interpretativas conforme a la Constitución; c) y se hubiesen empleado mayores esfuerzos para conseguir una argumentación final unánime y no tanto para conseguir una mayoría frágil sobre la sentencia.

En cualquier caso, ello no empece para retomar la idea de diálogo del Tribunal Constitucional con los distintos operadores jurídicos y, en particular, para advertir de una necesaria colaboración entre la doctrina y la jurisprudencia a la hora de construir categorías dogmáticas que den una explicación racional y coherente a la evolución de nuestro Estado Autonómico.

$* * *$

TITLE: The Statute of Catalonia through the individual votes to the judgement of the Constitutional Court 31/2010, of 28 june

ABSTRACT: This study aims to contribute to the analysis of the Constitutional Court Judgement 31/2010 of the Statute of Autonomy of Catalonia, through the technique of individual votes. To do so, as a guide, highlights the significance of the vote compared to the actual operation of the Constitutional Court, to the development of present and future doctrine, and its influence on the rest of legal operators. The article focuses both on the technical of the votes held in the Judgement 31/2010 and the change about the Judgement 137/2010, as in the content of the vote. The content, that goes beyond the analysis of the affected areas, to also influence on institutional position of the Constitutional Court. 
KeYwords: Constitutional Court, individual votes, the Statute of Autonomy, State Autonomy, interpretive judgments

RESUMEN: El presente estudio pretende contribuir al análisis de la Sentencia 31/2010 del Tribunal Constitucional sobre el Estatuto de Autonomía de Cataluña, a través de la técnica de los votos particulares. Para ello, como hilo conductor, se pone de relieve el significado de los votos respecto al propio funcionamiento del Tribunal, a la elaboración de su doctrina presente y futura, y a su influencia sobre el resto de operadores jurídicos. El artículo se centra tanto en la técnica de los votos llevada a cabo en la Sentencia 31/2010 y el cambio operado al respecto en la Sentencia 137/2010, como en el propio contenido de los votos. Un contenido que trasciende el análisis de los ámbitos estatutarios afectados para incidir, asimismo, en la propia posición institucional del Tribunal Constitucional.

Palabras Clave: Tribunal Constitucional; Votos particulares; Estatuto de Autonomía; Estado Autonómico; Sentencias interpretativas.

FeCHA DE RECEPCIÓN: 09.01.2011. FeCHA DE ACEPTACIÓN: 26.01.2011

UNED. Teoría y Realidad Constitucional, núm. 27, 2011, pp. 315-344. 
08 12/05/2011 7:26 Página 344

(8) 